\title{
Sleeping position and sudden infant death syndrome in Norway 1967-91
}

\author{
Lorentz M Irgens, Trond Markestad, Valborg Baste, Patricia Schreuder, Rolv Skjærven, \\ Nina Øyen
}

Medical Birth Registry of Norway, Department of Public Health and Primary Health Care, University of Bergen and National Institute of Public Health, Norway

L M Irgens

V Baste

P Schreuder

$\mathrm{N}$ Øyen

Department of Paediatrics, University of Bergen

T Markestad

Section for Medical Informatics and Statistics, University of Bergen R Skjærven

Correspondence to: Professor L M Irgens, Medical Birth Registry of Norway, Armauer Hansen Building, Haukeland Hospital, N-5021 Bergen, Norway.

Accepted 7 February 1995 varying, relative risk of SIDS in prone sleeping seems firmly established. However, the issue whether the association is causative or related to a confounding mechanism has not yet been clarified. Thus, the preventive potential of non-prone sleeping is not obvious. The accumulating evidence that it is potentially hazardous to place babies in the prone sleeping position precludes a randomised controlled trial. The issue may, however, be addressed by careful epidemiological surveillance of the sleeping position and SIDS rates in infant populations, preferably covering observations of wide ranges for both variables.

Such epidemiological surveillance has been conducted in Norway. An unofficial recommendation from paediatricians in January 1990 that prone sleeping in infancy should be avoided in order to prevent SIDS, might have caused a change in how parents place their babies, a change that eventually might be paralleled by the SIDS rates. The aim of the present study was to investigate patterns of infants' sleeping position in Norway 1970-91 and relate, in an ecological design, sleeping position to SIDS rates.

\section{Subjects and methods}

Since the early 1980 s, the Medical Birth Registry of Norway has routinely monitored the occurrence of SIDS in the country, based on information from death certificates linked with the registry. ${ }^{16}$ The present study was based on a comprehensive revision of all postperinatal death certificates in Norway ${ }^{17}$ pertaining to the birth cohorts 1967-91.

The design was that of a retrospective

Around 1970, the view evolved that newborn babies and infants, in general, should be placed in a prone sleeping position, ${ }^{1}$ and mothers were advised accordingly. Early on it was debated whether prone sleeping might cause an increased risk for sudden infant death syndrome (SIDS). However, two case-control studies in the early 1970s failed to prove any increased odds ratio related to prone sleeping. ${ }^{2} 3$ The recommendation was not questioned again until 1985 when Saternus reported an odds ratio of 4.6 (confidence interval (CI) 2.6 to $8 \cdot 3$ ), ${ }^{4}$ followed by similar studies in Australia, ${ }^{5-10}$ The Netherlands, ${ }^{11}$ France, ${ }^{12}$ Hong Kong, ${ }^{13}$ the $\mathrm{UK},{ }^{14}$ and New Zealand. ${ }^{15}$ An increased, but ecology study. The unit of observation was the group of infants born at a specified maternity institution during a specified period of time. Each unit of observation was characterised by the occurrence of SIDS as the dependent variable and the proportion of prone sleeping (that is, on the belly) at 3 months of age, together with five other potential risk factors, as independent variables.

Sleeping position in the infant population was assessed in an ad hoc survey carried out in November-December 1992 employing a one page postal questionnaire which was sent to a sample of mothers who had given birth in one of the 20 largest maternity institutions in 


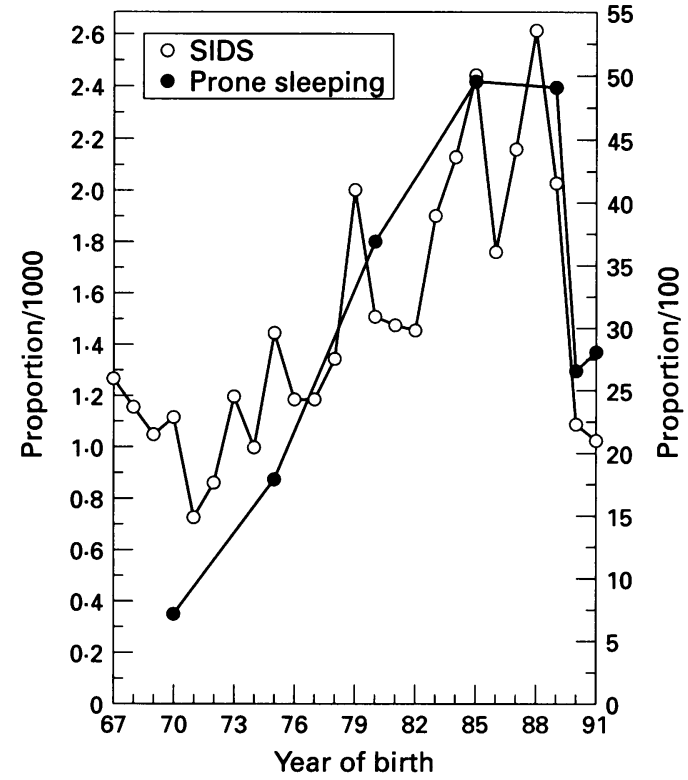

Figure 1 Occurrence (proportion/100 infants) of sleeping in prone position at the age of 3 months and occurrence of SIDS (proportion/1000 survivors of the perinatal period) by year of birth. Data obtained from the 20 largest maternity institutions in Norway 1967-91.

Norway in the survey years of 1970, 1975, $1980,1985,1989,1990$, and 1991. The annual numbers of births in these institutions ranged between 700 and 5000 . For each year and institution, 250 mothers were randomly sampled from the registry among all mothers of infants weighing $2500 \mathrm{~g}$ or more, without any reported birth defect, and surviving the first year of life; altogether there were 34799 mothers.

The questionnaire did not hold any information by which the responder could be identified. In one of the 10 questions, the parents were asked how they 'usually put the baby to sleep when he/she was approximately 3 months old' with the following options: 'on the belly', 'on the back', 'on the side', 'equally often on the side as on the back', and 'equally often on the back, on the side and on the belly'. In addition, the questionnaire identified the maternity institution and held information on the infant's date of birth and birth weight as well as mother's and father's years of birth. Furthermore, questions were included on how the infant was placed just after birth, why the parents used one position and not the other, how well the mother remembered the sleeping position, and about breast feeding and parental smoking.

Secular trends in the occurrence of SIDS were compared with the proportions of prone sleeping position. However, as the aetiology of SIDS is probably also related to a number of other risk factors, similar comparisons were performed for secular trends in five other independent variables, reported to be associated with an increased risk ${ }^{18}$ : the proportions of young mothers ( $<20$ years), high birth orders $(3+)$, low birth weight $(<2500 \mathrm{~g})$, smoking mothers (during pregnancy), and infants breast fed for less than three months. Data on the two latter variables were derived from the questionnaire, while data on the three former were derived from the registry.
To assess the extent to which possible secular trends were caused by diagnostic biases related to a transfer of cases between diagnostic categories, secular trends in the total mortality were also assessed. Both cohort based total postperinatal mortality and cohort based total mortality occurring between the 105 th and 125th day of life, the period in which the SIDS fraction of all deaths is highest, ${ }^{16}$ were considered.

Simple and multiple regression analyses ${ }^{19}$ were performed with the occurrence of SIDS pertaining to a maternity unit and to a period including the survey year as the dependent variable. The occurrence of SIDS was calculated as a proportion defined as the number of SIDS cases occurring in the cohorts born in that institution in the survey year as well as the year before and the year after, divided by the number of all infants of the same cohorts surviving the first week of life. The SIDS proportion for the survey year 1989 was based on the incident cases in the birth cohorts of 1988 and 1989. Likewise, the two survey years 1990 and 1991 were combined both for the calculation of the SIDS proportions and the proportions of prone sleeping, as well as for the calculation of the other independent variables. Each observation was weighted by the inverse of the variance of the occurrence of SIDS. As the aetiology of SIDS is assumed to be multifactorial, a strong association between SIDS and prone sleeping in the various units of observation was not expected; geographical differences might be caused also by other risk factors. For that reason, potential associations between the SIDS proportion and the independent variables assessed in the regression analyses were not based on the absolute proportions per se, but rather differences in proportions from one survey year to the next.

\section{Results}

Of 34779 mothers who received the questionnaire, $24438(70 \cdot 2 \%)$ responded, and among these, $22608(92.5 \%)$ replied that they were certain about the sleeping position when the infant was approximately 3 months old.

The proportion of prone sleeping at 3 months of age increased continuously from $7.4 \%$ in 1970 to $49.6 \%$ in 1985 and $49.1 \%$ in 1989. Subsequently, the proportion dropped to $26.8 \%$ in 1990 and $28.3 \%$ in 1991 (fig 1 ).

The SIDS proportion among infants born in the 20 institutions followed a pattern increasing from $1 \cdot 1 / 1000$ in 1970 to $2 \cdot 6$ in 1988 , and 2.0 in 1989 . Then, the proportion dropped to 1.1 in 1990 and 1991 (fig 1). The total postperinatal mortality (after 1977), as well as the total mortality occurring from the 105th through the 125th day of life, followed a similar pattern (fig 2).

Secular trends, based on data from the same 20 institutions, in the proportions of young mothers $(<20$ years), high birth orders $(3+)$, low birth weights $(<2500 \mathrm{~g})$, smoking mothers, and infants breast fed less than three months were not consistent with those observed in the proportion of SIDS (fig 3). 




Figure 2 Occurrence (proportion 1000 survivors of the perinatal period) of postperinatal death of SIDS, and of death from the 105th through the 125th day of life by year of birth in Norway 1967-91.

In a weighted linear regression analysis of changes in the SIDS proportion on changes in the proportion of prone sleeping, comprising the whole period, a positive association was observed $(r=0.55, \mathrm{p}<0.001)$ (fig 4$)$.

To avoid confounding due to other factors that might have similar secular trends, this analysis was split into five subsets which covered the changes 1970-5, 1975-80, $1980-5,1985-9$, and 1989-90/1 respectively, thus focusing on geographical rather than temporal associations (fig 4). In 1970-5, all changes in prone sleeping proportions represented increases, but the SIDS proportions did not change accordingly. In 1975-80, greater increases in prone sleeping proportions were observed and most of the institutional units experienced higher SIDS proportions, but the association was not statistically significant. Particularly in 1985-9, some units experienced increases in prone sleeping proportions while others experienced decreases. However, the SIDS proportions did not change accordingly. In 1989-90/1, prone sleeping proportions decreased in all units, while the SIDS proportions decreased in all but four units $(r=0.60$, $\mathrm{p}=0.005$ ).

In simple regression analyses of the SIDS proportion on the other five independent variables (proportions of young mothers, high birth orders, low birth weight, smoking, and breast feeding) comprising all five intervals, no significant associations were observed. In a final multivariate regression analysis comprising all six independent variables and covering all five intervals, proportion of prone sleeping remained as the only significant variable and adjustment for the other five variables did not change the result.

\section{Discussion}

As far as we know, this is the only national investigation until now of infants' sleeping patterns and their relation to SIDS. The intention was to obtain, over an extended period of time, information on the sleeping patterns of a normal infant population, the population at risk of dying from SIDS. The putative causative factor, that is, sleeping position, was assessed by a questionnaire sent to a random sample of all mothers. The restrictions concerning birth weight, birth defects, and survival were employed to avoid the consequences of atypical counselling with respect to sleeping position as a result of these conditions. As only mothers of surviving children were addressed, no bias caused by guilt, and thus perhaps attempts to avoid answering 'prone sleeping', would seem likely.

The relatively high response rate $(70 \cdot 2 \%)$, obtained without the possibility of a reminder, is attributable to the fact that SIDS has been an issue of considerable public concern in Norway, probably due to the high and increasing occurrence. Admittedly, the non-responders may represent a biased sample, possibly with a higher proportion of non-affluent mothers. However, any consequences in terms of a spurious association would be difficult to predict.

The survey was retrospective, but $92 \cdot 5 \%$ of the mothers reported that they remembered very well the position in which they usually placed their baby. The low proportion of prone sleeping in $1970(7.4 \%)$ is in agreement with the fact that non-prone sleeping was the traditional infant sleeping pattern in Norway.

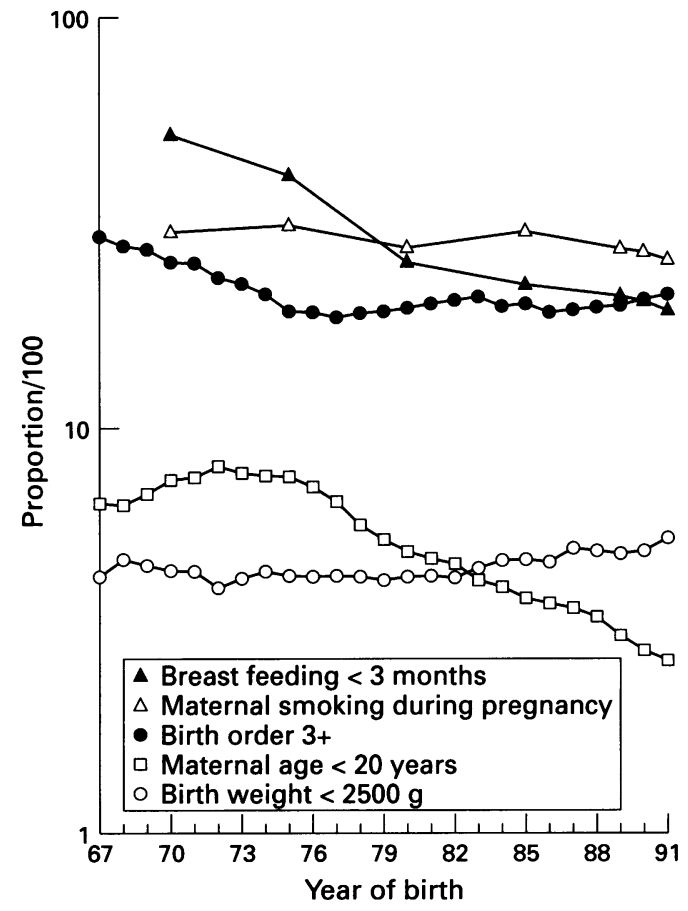

Figure 3 Occurrence (proportion/100) among infants born in the 20 largest maternity institutions in Norway of breast feeding $<3$ months and maternal smoking during pregnancy (data from the questionnaire), and of birth order $3+$, maternal age $<20$ years, and birth weight $<2500 \mathrm{~g}$ (data from the Medical Birth Registry of Norway by year of birth). 
The effect was measured as secular trends in the SIDS proportion. The procedures employed to identify all SIDS cases on the basis of death certificates of all postperinatal deaths have recently been accounted for elsewhere. ${ }^{17}$ Nevertheless, a discussion of false positive and false negative cases will continue because of the lack of positive case criteria. However, the increasing SIDS rate in Norway until 1989 as well as the distinctive decrease from 1989 to 1990 were reflected in the total
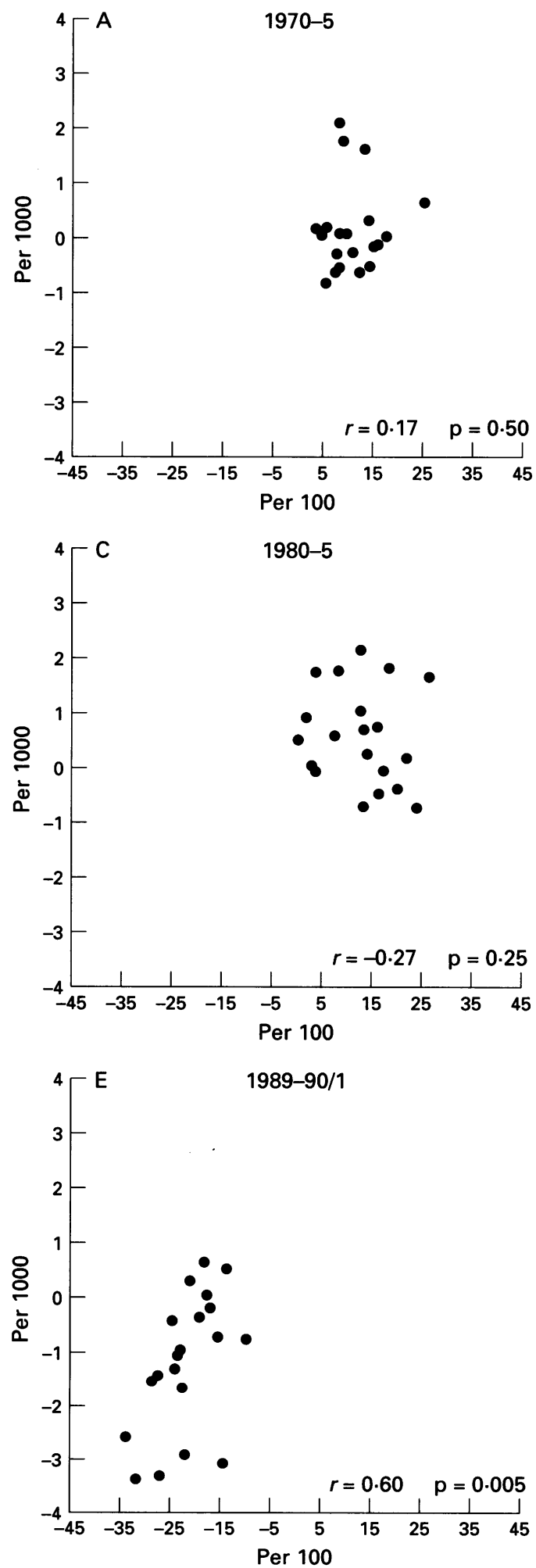

mortality rate, both in the postperinatal period and from the 105th through the 125th day of life, when the fraction of all deaths represented by SIDS is highest, ${ }^{16}$ ruling our false secular trends caused by a transfer of diagnosis. To the extent the decrease from 1988 $(2 \cdot 6)$ to $1989(2.0)$ does not reflect random variation, a large fraction of children born in 1989 was actually affected by the change in sleeping position recommended already in January 1990.
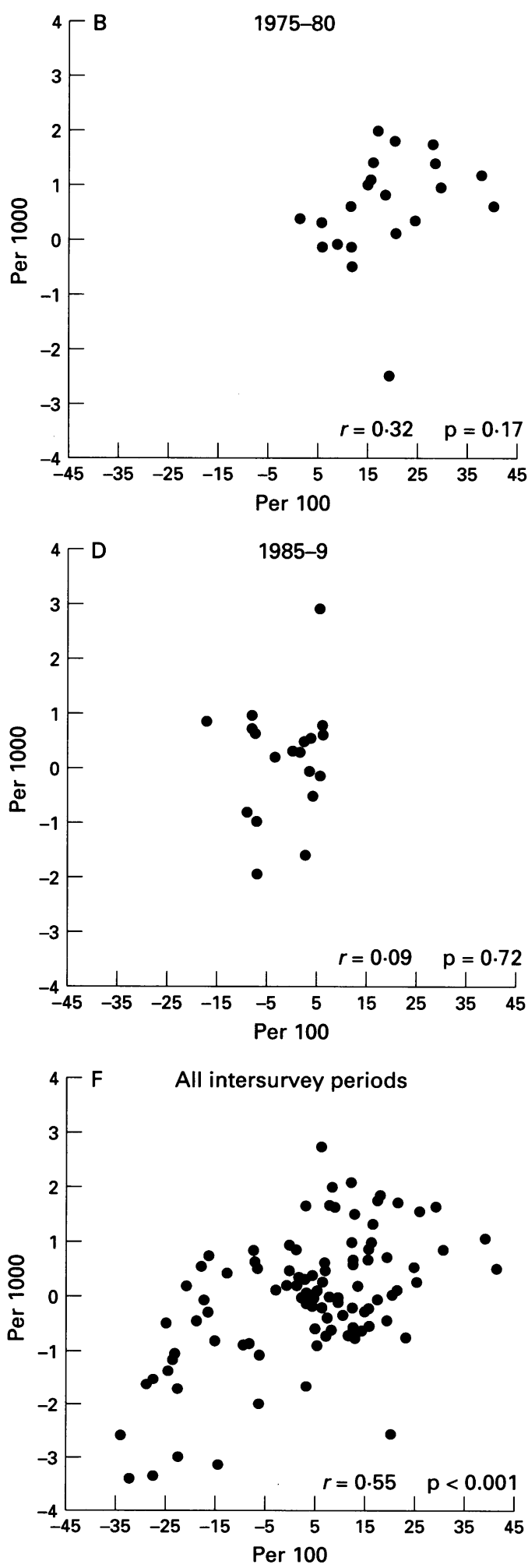

Figure 4 Associations between differences from one survey year to the next in the proportion of prone sleeping ( $x$ axis) and in the proportion of SIDS (y axis). Maternity unit specific observations for each intersurvey period $(A-E)$ and for all intersurvey periods $(F)$. 
The study confirmed the association between prone sleeping and SIDS, observed in a series of previous studies. ${ }^{4-15}$ However, such an association does not necessarily represent a causal relationship. Thus, one could speculate that the association might be the effect, for example, of a brain stem lesion that both causes SIDS and, before death, a preference for prone sleeping. If this were the case, a reduction in the prone sleeping proportion of all infants would not necessarily reduce the SIDS rate in the population. However, it appeared that an abrupt reduction of prone sleeping in Norway was followed by an equally abrupt drop in the SIDS rate. These observations suggest that the association represents a causal relationship of considerable interest from a preventive point of view, an inference supported by similar observations in Avon, $\mathrm{UK}^{20}$ and New Zealand. ${ }^{21}$

The finding of a significant temporal, but not a geographical association is confusing. However, the SIDS proportions in each unit of observation were based on small numbers of cases, involving considerable uncertainty. Furthermore, there is no reason to believe that the strength of the association in terms of an odds ratio, should be constant and independent of other factors, for example, related to period. ${ }^{22}$ This question has been addressed in a case-control study in Hordaland County, Norway, $1987-92 .{ }^{23}$ In the three years before the recommendation to avoid prone sleeping, prone sleeping was observed in $64 \%$ of the controls with an odds ratio of 1.6 (CI 0.7 to 3.7 ) against 8.5 (CI 2.6 to 28.7 ) in the three years subsequent to the recommendation when $8 \%$ of the controls were sleeping prone, consistent with a lack of an association before 1989 . Probably, the infants placed prone after a general recommendation is given to avoid that position, are different from those placed prone before such a recommendation is given and could, for various reasons, be at a higher risk for SIDS. On the one hand, one may speculate whether parents who do not receive the message may be unfortunate also in other ways, thus representing a higher risk of SIDS for other reasons. On the other hand, the infants remaining in a prone position might represent infants more comfortable in such a position, and if this preference is related to increased risk, more or less independent of the sleeping position, the increased odds ratio is inevitable. Even if the latter mechanism is less likely or perhaps less frequent, due to the great drop in the SIDS rate observed after the change of sleeping position, it cannot be completely ruled out.

In conclusion, accumulating evidence comprising previous studies as well as the present seems to establish prone sleeping position as an important risk factor in SIDS. Thus, a considerable number of SIDS cases would seem attributable to prone sleeping through the last 20 years. All epidemiological questions related to prone sleeping are not yet resolved, however, and the lack of a geographical association before the great incidence decrease in 1990 represents an enigma. Furthermore, the mechanisms involved are far from clarified and offer challenges to physiologists. However, even without mechanistic knowledge, the recommendation to avoid prone sleeping is justified on the basis of existing evidence and should be propagated accordingly.

The study was supported by grants from The Norwegian SIDS The study was supported by grants from The Norwegian SIDS Association, The Norwegian Research Council, the
of Health, and the Bergen Red Cross Organisation.

We are grateful to parents from the Norwegian SIDS associWe are grateful to parents from the Norwegian SIDS associ-
ations for their help in the administration of the postal ations for their help in the administration of the postal
questionnaire and all the parents who contributed by answering it.

1 Gleiss J. Die Vor-und Nachteile der Bauchlage bei Neugeborenen und jungen Säuglingen. Dtsch Med Wochenschr 1969; 94: 2449-52.

2 Carpenter RG. Session I. In: Camps FE, Carpenter RG, eds. Sudden and unexpected deaths in infancy (cot death). Bristol: John Wright, 1972: 7-15.

3 Froggatt $P$. Epidemiological aspect of the Northern Ireland study. In: Bergman AB, Beckwith JB, Ray CG, eds. Proceedings of the second international conference on causes of sudden death in infants. Seattle: University of Washington sudden death in infants.

4 Saternus K-S. Pløtzlicher Kindestod: eine Folge der Bauchlage? Festschrift Professor Leithoff. Heidelberg, Germany: Kriminalistik Verlag, 1985: 67-81.

5 Cameron MH, Williams AL. Development and testing of scoring systems for predicting infants with high risk of sudden infant death syndrome in Melbourne. Australian Paediatric fournal 1986; 22 (suppl): 37-45.

6 Beal S. Sleeping position and SIDS. Lancet 1988; ii: 512 .

Tonkin S, Hassal I. Infant sleeping position and cot death Australian Paediatric fournal 1989; 25: 376-7.

8 Nelson EAS, Taylor BJ, Mackay SC. Child care practices and the sudden infant death syndrome. Australian Paediatric fournal 1989; 25: 202-4.

9 Beal S, Porter C. Sudden infant death syndrome related to climate. Acta Paediatr Scand 1991; 80: 278-87.

10 Dwyer T, Ponsonby A-LB, Newman NM, Gibbons LE. Prospective cohort study of prone sleeping position and Prospective cohort study of prone sleeping position and

11 Jonge GA de, Engelberts AC, Koomen-Liefting AJM, Kurtense PJ. Cot death and prone sleeping position in the Netherlands. $B M \mathcal{F} 1989 ; 298: 722$.

12 Senecal J, Roussey M, Defawe G, Delahaye M, Piquelnal B. Procubitus et mors subile inattendue du nourrison. Arch Fr Pediatr 1987; 44: 131-6.

13 Lee NNY, Chan YF, Davies DP, Lau E, Yip DCP. Sudden infant death syndrome in Hong Kong: confirmation of low incidence. $B M F$ 1989; 298: 721 .

14 Fleming PJ, Gilbert R, Azaz Y, et al. Interaction between bedding and sleeping position in the sudden infant death syndrome: a population based case control study. $B M 7$ 1990; 301: 85-9.

15 Mitchell EA, Taylor BJ, Ford RPK, et al. Four modifiable and other major risk factors for cot death. New Zealand Study. F Paediatr Child Health 1992; 28 (suppl 1): S3-8.


infant death syndrome and other causes of post perinatal mortality in Norwegian birth cohorts 1967-1984. Acta Paediatr Scand 1989; 78: 228-32.

17 Øyen N, Irgens LM, Skjærven R, Morild I, Markestad T, Rognum TO. Secular trends of sudden infant death syndrome in Norway, 1967-1988. Application of a method of case identification to Norwegian registry data. Paediatr Perinat Epidemiol 1994; 8: 263-81.

18 Irgens LM, Skjærven R. Sudden infant death syndrome and post perinatal mortality in Norwegian birth cohorts 1967-1980. Acta Paediatr Scand 1986; 75: 523-9.

19 Dixon WS, ed. BMDP statistical software. Berkeley, California: University of California Press, 1990

20 Wigfield RE, Fleming PJ, Berry PJ, Rudd PT, Golding J. Can the fall in Avon's sudden infant death rate be explained by changes in sleeping position? BMF 1992; 304: 282-3.

21 Mitchell EA, Ford RPK, Taylor BJ, et al. Further evidence supporting a causal relationship between prone sleeping position and SIDS. $尹$ Paediatr Child Health 1992; 28 (suppl 1): S9-12.

22 Mitchell EA. Sleeping position of infants and the sudden infant death syndrome. Acta Paediatr 1993; 82 (suppl 389): 26-30.

23 Markestad T, Skadberg B, Hordvik E, Morild I, Irgens LM. Sleeping position and SIDS, effect of an intervention program to avoid prone sleeping. Acta Paediatr 1995; 84: 375-8. 